\title{
ANÁLISE DO PROCESSO DE DEFINIÇÃO DE REQUISITOS EM SOFTWARE COM UM ESTUDO DE CASO EM UMA EMPRESA DE METAL DESIGN
}

Amanda Mendonça (amandacaqm@gmail.com) - Universidade de Brasília

Ananda Dantas (ananda.sd2@gmail.com) - Universidade de Brasília

Sanderson Barbalho (scmbbr@yahoo.com.br) - Universidade de Brasília

\section{RESUMO}

O Processo de Desenvolvimento de Produto (PDP) unido a ferramentas baseadas na tecnologia da informação (TI) é capaz de fornecer um instrumento de suporte a empresas para otimização da produção e alcançar maior vantagem competitiva no mercado. Assim, o presente trabalho tem como objetivo analisar o processo de levantamento de requisitos necessários para um produto de software e estudar o contexto do Planejamento e Controle da Produção(PCP) de uma pequena empresa do Distrito Federal (DF). A metodologia aplicada tratou-se de uma pesquisa exploratória para compreensão dos conceitos envolvidos e um estudo de caso para o entendimento do funcionamento de uma empresa real, foram realizadas visitas técnicas na instituição escolhida e a aplicação de um instrumento de coleta de dados semiestruturado sobre os conceitos de PCP. Com esse estudo foi possível levantar um diagnóstico sobre a forma que a empresa planeja e controle o setor produtivo a fim de iniciar um estudo para o desenvolvimento de uma ferramenta inovadora de TI que apoie a gestão de mico e pequenas empresas brasileiras.

Palavras chave: Processo de Desenvolvimento de Produto, Planejamento e Controle da Produção, Software. 


\section{INTRODUÇÃ̃}

O Processo de Desenvolvimento de Produtos (PDP), para Rozenfeld et. al. (2006), ocorre na interface entre uma empresa e o mercado, e o seu principal objetivo é a identificação e, inclusive a antecipação, das necessidades do mercado para propor soluções que as atendam. $\mathrm{O}$ grande segredo desse processo é diminuir as incertezas por meio da qualidade das informações, além de controlar constantemente os requisitos a serem atendidos e vigilar as possíveis mudanças do mercado a cada momento de decisão (ROZENFELD et. al., 2006, p. 7).

Nos modelos de referência amplamente discutidos na academia, considera-se o contexto de uma grande empresa criando ou aprimorando produtos de sua carteira, no entanto, a compreensão dos conceitos e da estruturação sequencial e lógica é essencial para o desenvolvimento de produtos no âmbito de pequenas empresas ou grupos de pesquisadores que desejam criar algo novo.

Portanto, as três macro fases do PDP são: o Pré-Desenvolvimento, o Desenvolvimento e o PósDesenvolvimento. A primeira delas engloba o Planejamento Estratégico dos produtos e o Planejamento do Projeto, enquanto a segunda, o Projeto Informacional, o Projeto Conceitual, o Projeto Detalhado, a Preparação da Produção e o Lançamento do Produto, e, por fim, a terceira macro fase consiste em acompanhar o projeto/processo e descontinuar o produto (ROZENFELD et. al., 2006).

Laurence e Page (1984) consideram que o planejamento de novos produtos envolve, principalmente, a determinação dos objetivos básicos desses futuros produtos e o tipo de especificações que serão feitas. Nessa fase de definição de requisitos, é essencial que as atividades sejam desempenhadas de forma cautelosa e sistemática, e por isso existem os modelos e métodos, para guiarem esse processo (ULIANA et. al., 2013).

Tais modelos de PDP, para Uliana et. al. (2013), são úteis para driblar situações recorrentes na criação de produtos que ficam restritos a ideia de uma única pessoa, ou a viabilidade técnica de funcionamento, uma vez que, ao aplicar o processo sistematicamente, serão avaliadas as possibilidades legais, de patente, viabilidade de mercado, dentre outras.

Para um produto de software, a realidade não é diferente, muitas vezes o que o desenvolvedor ou a equipe de gerenciamento do projeto de desenvolvimento de software idealizam para o produto final não é exatamente o que o cliente deseja ou necessita. Por isso, a aplicação de 
métodos e ferramentas de PDP, com suas adaptações consistentes para a realidade de um produto intangível é de grande relevância.

Segundo Herzwurm e Schockert (2003) os métodos de engenharia de requisitos de software buscam transformar os requisitos do usuário em especificações formais e modelos a serem utilizados no desenvolvimento do sistema. E com o passar do tempo, esses métodos estão menos focados na formalização e na documentação das etapas do processo e mais preocupados em satisfazer reais necessidades dos clientes e usuários.

Diante do contexto exposto, o presente artigo objetiva analisar o processo de levantamento de requisitos necessários para um produto de software e estudar o contexto do Planejamento e Controle da Produção de uma pequenas empresas do Distrito Federal (DF). Para tanto, foi realizado um levantamento bibliográfico relacionado aos conceitos, procedimentos e métodos relacionados a etapa do PDP de levantamento de requisitos voltados para a área de software, apresentado na seção seguinte. Na sequência é apresentada a metodologia de trabalho e em seguida o estudo de caso realizado na empresa com o perfil delimitado.

\section{REVISÃO TEÓRICA}

\subsection{Definição de Requisito do Produto}

A macro frase de Pré-planejamento é importante para todo processo de desenvolvimento do produto, sendo apenas mais completa em casos de produtos com uma alta complexidade. Essa etapa envolve a fase de planejamento estratégico de produtos e o planejamento do projeto, tratase então de desdobrar a estratégia empresarial em possibilidades de atuação em termos de produto e compreender o mercado e os concorrentes (ROZENFELD et. al., 2006).

Ainda no modelo de referência de Rosenfeld et. al. (2006), ao entrarmos na macro fase de Desenvolvimento, deparamo-nos com a fase do Projeto Informacional, que engloba as atividades: revisar e atualizar o escopo do produto, detalhar o ciclo de vida do produto e definir seus clientes, identificar requisitos dos clientes do produto, definir requisitos do produto, definir especificações do produto, monitorar viabilidade econômica, e, por fim, avaliar e aprovar fase. Tais atividades são representadas na Figura 1: 


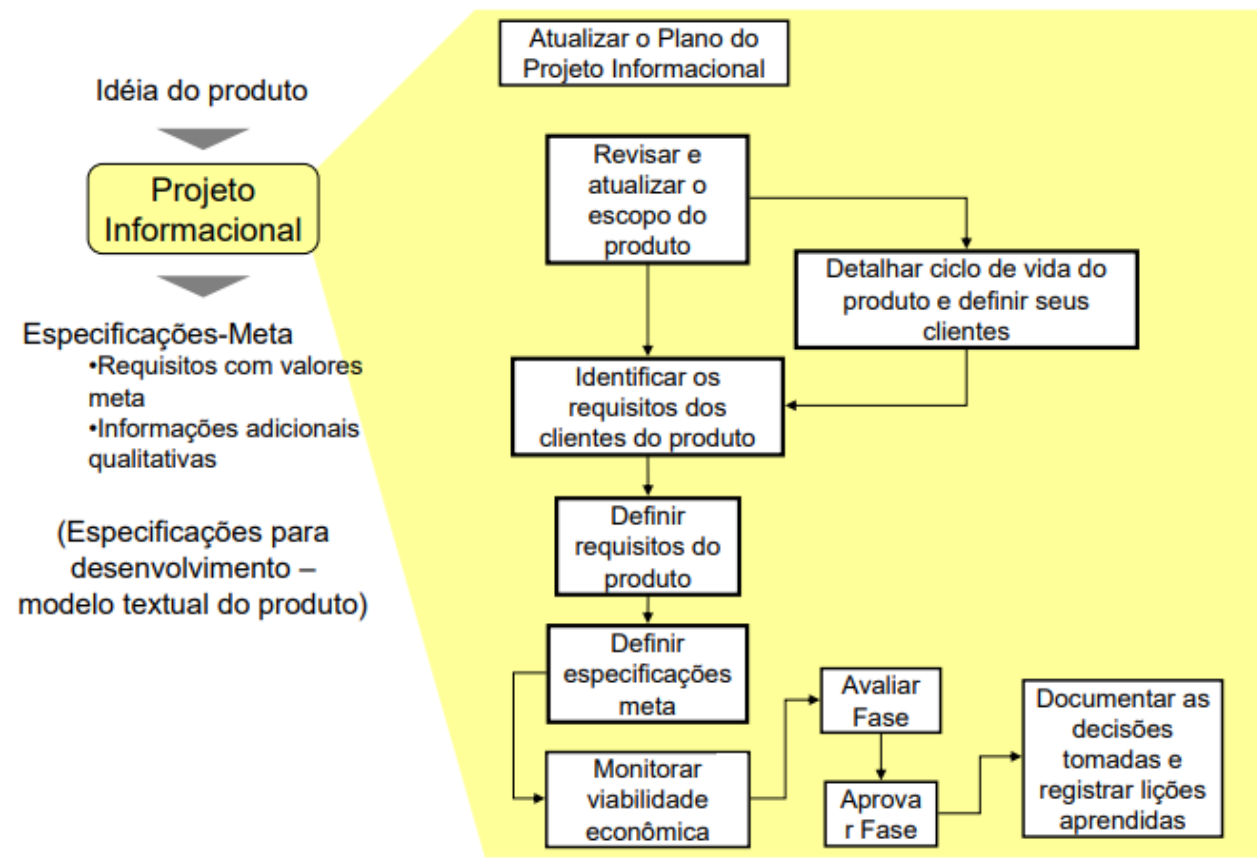

Figura 1: Estrutura do Projeto Informacional. Fonte: Rosenfeld, et. al. (2006).

É exatamente ao executar esses marcos do projeto, referentes ao Projeto Informacional, que os desenvolvedores irão testar suas ideias com os potenciais clientes, para confirmar a demanda do mercado, e transformar a visão desse público-alvo em informações valiosas para a equipe técnica.

Para Nickel (2010), o levantamento e tratamento dos requisitos do cliente envolvem as principais decisões de projeto de produtos e, por isso, há uma vasta literatura a respeito de procedimentos sistemáticos indicados nesse contexto.

Fonseca (2000) entende que o Projeto Informacional inicia-se com o estabelecimento de um problema de projeto, que será investigado com os próprios clientes em uma pesquisa de mercado, e esta, por sua vez, "parte de uma informação mínima sobre as características do produto que vai ser projetado, ganhando conhecimento sobre o mesmo na medida que se vai conformando a ideia do novo produto" (FONSECA, 2000, p. 33).

A tradução do que o cliente falou para uma linguagem que poderá ser utilizada pela equipe de engenharia ou de desenvolvimento do produto em si é um processo delicado e crítico, onde as terminologias precisam estar bem alinhadas. O quadro abaixo esclarece esses conceitos: 
TABELA 1 - Conceitos no Projeto Informacional

\begin{tabular}{|l|l|}
\hline Categoria da Informação & Significado \\
\hline Necessidade & Declaração direta do usuário ou clientes \\
\hline Requisito do usuário & Necessidade, levada à linguagem de projeto \\
\hline Requisito de projeto & Requisito mensurável, aceito para o projeto \\
\hline Especificação de projeto & Requisito de projeto, convenientemente especificado \\
\hline
\end{tabular}

Fonte: Fonseca (2000).

Um software pode ser caracterizado como estruturas de dados que possibilitam os programas a manipular informações e como documentos que descrevem a operação e o uso dos programas. Ao iniciar um projeto de software, os objetivos e o escopo devem ser estabelecidos, assim como suas restrições e soluções e, para isso, o desenvolvedor de software e o cliente devem reunir-se para discussão dessas questões. (PRESSMAN, 1982).

De acordo com Pressman, para um bem-sucedido desenvolvimento de software, uma compreensão dos seus requisitos é fundamental. Essa análise permite o aprimoramento das suas alocações e a construção de modelos de processos, dos dados e dos domínios comportamentais que serão tratados pelo software.

Dentro do contexto do projeto de software, preliminar e detalhado, diferentes atividades são desenvolvidas. Conforme Pressman, além dos projetos procedimental, arquitetural e de dados, muitas aplicações modernas têm uma atividade de projeto distinta: O projeto de interface. Ele estabelece o layout e os mecanismos de interação para a relação homem-máquina. A relação entre os aspectos técnicos e gerenciais estão ilustrados na Figura 5. 


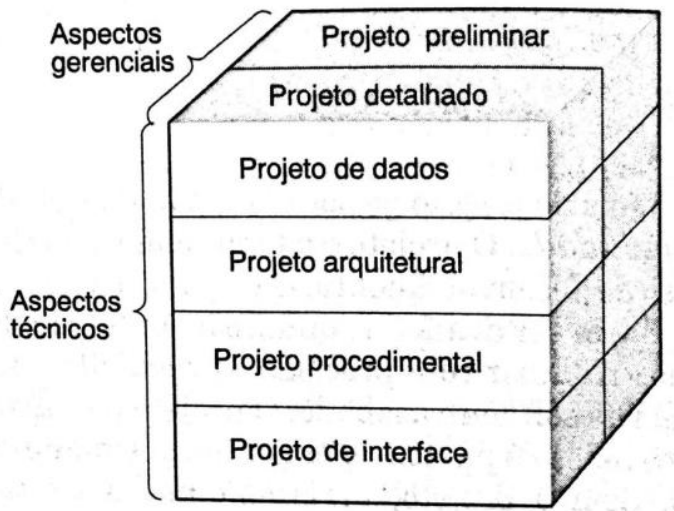

Figura 5: Aspectos do projeto de software. Fonte: Pressman e Bruce (1995).

Uma vez que a importância do projeto reside em sua qualidade, os fatores da qualidade do software focalizam em três aspectos: suas características operacionais, sua manutenibilidade e sua adaptabilidade a novos ambientes (PRESSMAN, 1982).

Em se tratando de desenvolvimento de software, essa etapa de levantamento de requisitos também é considerada de grande importância. Podemos entendê-la da seguinte forma:

\footnotetext{
"Os requisitos expressam as características e restrições do produto de software do ponto de vista da satisfação das necessidades do usuário e, em geral, independem da tecnologia empregada na construção da solução, sendo a parte mais crítica e propensa a erros no desenvolvimento de Software”. (MACHADO, 2016, p. 7)
}

Entendendo que os produtos de software podem ser instrumentos de aplicações de inovações tecnológicas, é válido compreender as abordagens que a inovação é vista pela academia. Maçaneiro e Cunha (2011) listam 2 abordagens primárias que que apresentam modelos de desenvolvimento do processo inovador. Uma abordagem é a tecnology-push, que entende que os avanços científicos podem ser responsáveis por desenvolver tecnologias para a sociedade. A outra abordagem é a market pull, onde o mercado, ou possíveis clientes, delineiam o desenvolvimento de novas soluções. 


\subsection{Planejamento e Controle da Produção}

Podemos entender gestão como o alinhamento entre planejamento, controle, organização e direção. Planejamento trata-se de se preparar para situações futuras, enquanto o controle envolve decisões de execução das operações. Organização diz respeito a ordem hierárquica estabelecida e, direção, a responsabilidade atribuída às lideranças. (FERNANDES e FILHO, 2010). Gerentes de produção são os funcionários da organização que exercem responsabilidade particular em administrar algum ou todos os recursos envolvidos pela produção, e administração da produção é o termo utilizado para as atividades, decisões e responsabilidades dos gerentes de produção (SLACK, 2002).

De acordo com MARTINS (2006), Planejamento e Controle da Produção (PCP) é uma área de tomada de decisão de manufatura, cujo objetivo se dá tanto no planejamento quanto no controle dos recursos do processo produtivo, a fim de gerar bens e serviços.

De acordo com Slack (2002), define-se "estratégia de operações como o padrão global de decisões e ações, que define o papel, os objetivos, e as atividades da produção de forma que estas apoiem e contribuam para a estratégia de negócios da organização".

O posicionamento estratégico da organização influencia em larga escala a sua capacidade de competir. Na elaboração da estratégia organizacional, é importante identificar os fatores críticos para o sucesso. Esses fatores são associados ao negócio da organização e são internos ou externos. A avaliação da organização, segundo esses fatores, permite a elaboração de estratégias focadas na melhoria do posicionamento competitivo da organização. (LUSTOSA, MESQUITA e OLIVEIRA, 2008).

Slack (2002) afirma que ao levantar os requisitos de um produto, inicia-se um projeto com um conceito e finaliza-o com sua tradução em uma especificação, algo que pode ser produzido, identificando as opções de viabilidade, aceitabilidade e vulnerabilidade.

É importante que a empresa defina o tipo de processo que será empregado no chão de fábrica, podendo eles ser por projeto, jobbing, lotes, massa, contínuo. A figura abaixo indica as situações mais favoráveis para empregar cada um desses processos: 


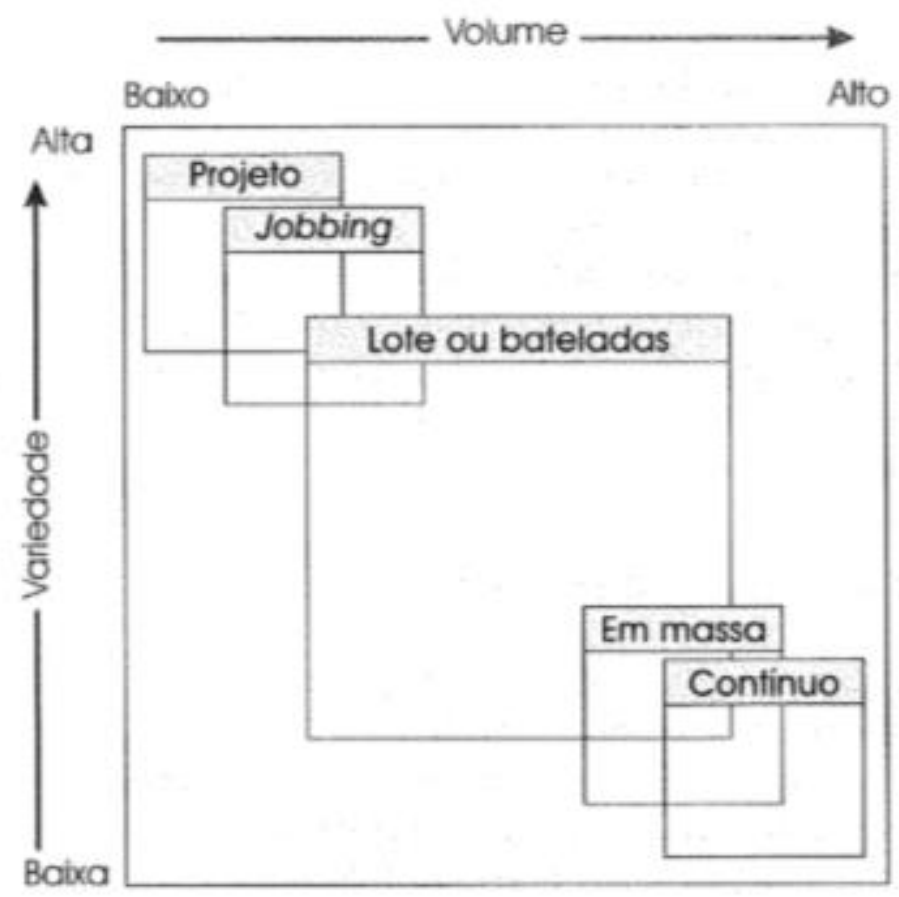

Figura 2: Tipos de Processos de Produção. Fonte: Slack (2002).

Após as decisões tomadas em um nível estratégico, entrando em um nível tático, dispomos de uma série de ferramentas com o intuito de planejar a controlar a produção de forma mais direta. Uma dessas ferramentas é o Programa Mestre de Produção (MPS), que traz uma declaração de quantidade e momento em que os produtos finais devem ser produzidos de acordo com dados de entrada, de acordo com a Figura 03.

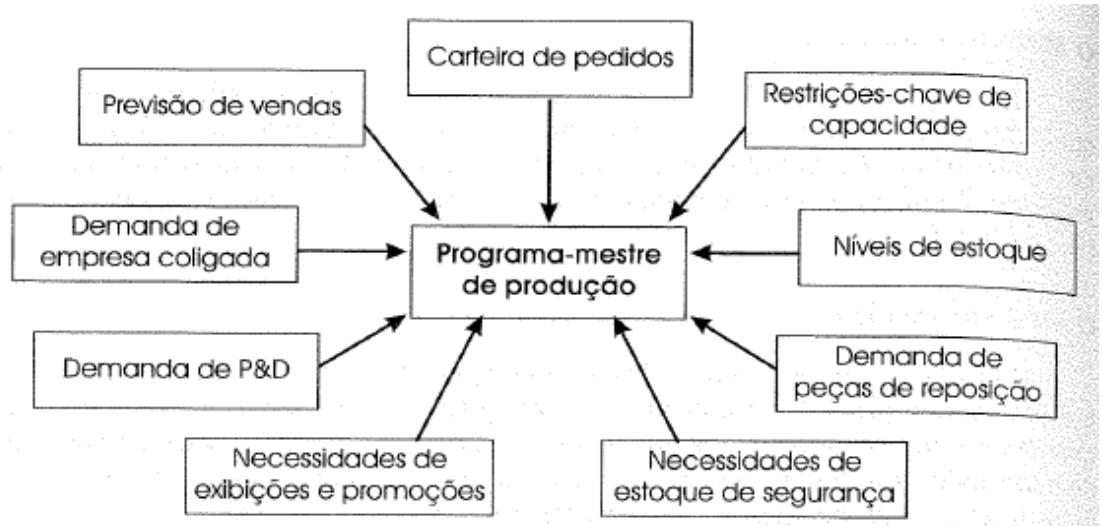

Figura 3: Tipos de Processos de Produção. Fonte: Slack (2002). 
O MPS coordena a demanda do mercado com os recursos internos da empresa de forma a programar taxas adequadas de produção de produtos finais. Balanceando suprimento e demanda de produtos acabados, período a período, considerando todas as suas diferentes fontes, possibilita ter uma visão de futuro da demanda e entender quais recursos serão necessários para satisfazer essa demanda. (CORRÊA,1997). Segundo Corrêa, há vários formatos de registro básico do MPS e cada software comercial escolhido terá o seu de acordo com as suas particularidades.

Assim, sabendo o objetivo final de produção, é possível realizar o Planejamento de Recursos de Produção (MRP), que trabalha com uma previsão de volume e tempo que as matérias-primas devem estar disponíveis (SLACK, 2002).

A demanda da empresa também precisa ser gerenciada e isso inclui esforços em cinco áreas principais: previsão da demanda, comunicação com o mercado, influência sobre a demanda, promessa de prazo de entrega, além de priorização e alocação (CORRÊA, 1997).

Planejar e controlar a produção são tarefas que requerem conciliação entre o fornecimento e a demanda, em termos de volume, tempo e qualidade. As atividades de PCP realizadas por uma empresa no curso prazo são: carregamento (definição do volume), sequenciamento (definição da prioridade das tarefas) e programação (definição do momento de início e fim) (SLACK, 2002).

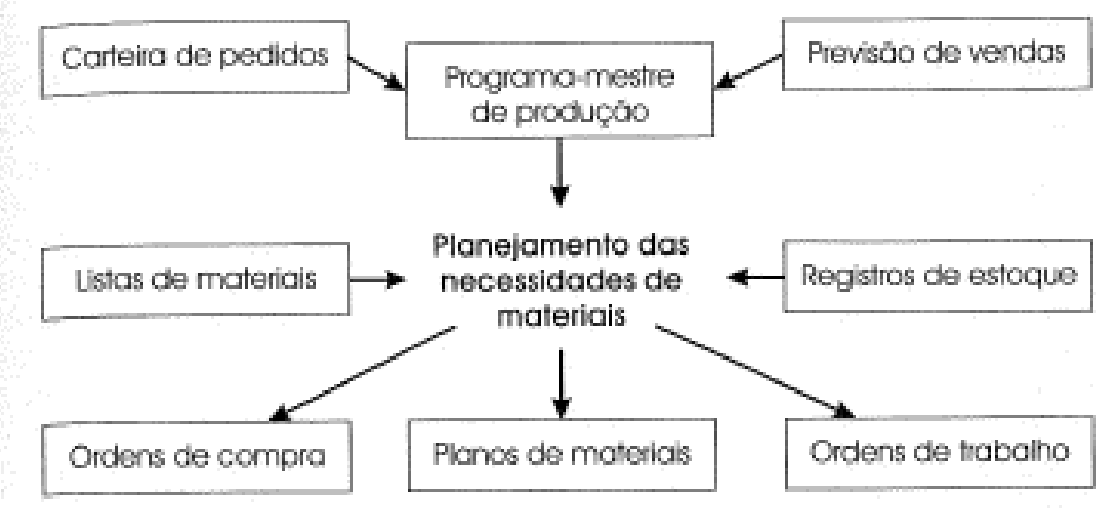

Figura 4: O programa-mestre de produção. Fonte: Slack (2002). 
As estruturas de produto vão definir o nível de burocracia que o sistema MRP vai impor. Estruturas com vários níveis indicam necessidade de muito estudo e observações, pois representam mais itens estocáveis e, portanto, mais entradas e saídas. Se a empresa tem um sistema produtivo linearizado como um fluxo contínuo, suas estruturas terão poucos níveis, uma vez que haverá poucas ocorrências de itens sendo estocados (CORRÊA, 1997).

\section{METODOLOGIA}

Neste trabalho, foi realizado um estudo de caso a fim de entender as necessidades dos clientes dentro de uma sistemática de desenvolvimento de um software para o planejamento e controle da produção em micro e pequenas empresas. Para isso, foi escolhida uma empresa de pequeno porte, localizada no DF que cria produtos diferenciados de metal design para a cidade que está situada e demais estados brasileiros.

Para Gil (2002), as pesquisas podem ser classificadas com relação ao seu objetivo e às técnicas empregadas. Nesse sentido, o presente artigo relata uma pesquisa exploratória no que diz respeito aos seus objetivos, de descobrir e entender melhor um contexto específico de interesse. De acordo com Prodanov e Freitas (2013), a pesquisa exploratória permite o estudo do tema sob diversos ângulos e aspectos, tais como levantamento bibliográfico e entrevistas com indivíduos que tiveram experiência com o problema pesquisado.

No que tange aos procedimentos técnicos utilizados, trata-se de um estudo de caso, onde procura-se guiar uma decisão ou um conjunto de decisões: por que elas são tomadas, como elas são implementadas e com que resultados (Schramm, 1971).

Os dados coletados foram obtidos a partir de um roteiro de 15 perguntas elaboradas com o intuito de reunir as características da empresa e os fatores que influenciam na sua forma de produção. Para responder esse questionário, foram realizadas visitas técnicas que possibilitaram a observação do ambiente de trabalho e entrevistas com os funcionários de cada área - vendas, layout, produção, administrativo financeiro. As perguntas contemplavam informações como a estratégia de produção, os elementos básicos de planejamento e controle da produção, a capacidade de curto médio e longo prazo e o método de controle de produção adotado pela empresa. 


\section{RESULTADOS E DISCUSSÃO}

Para o estudo de caso aqui apresentado, escolheu-se uma empresa de pequeno pote que, de acordo com o SEBRAE (2019), pode ser enquadra como tal baseado em seu faturamento anual. A partir dos dados recolhidos por meio do questionário, foi possível reunir informações a respeito do PCP da empresa.

De acordo com a classificação se Slack (2002) a produção da empresa caracteriza-se por ser jobbing, que, são linhas de produção que possuem alta variedade e baixo volume, cada produto compartilha recursos da operação com diversos outros, mas serão diferentes entre si em suas especificidades.

Além das análises possibilitadas pelo instrumento de coleta de dados, as visitas e as entrevistas realizadas forneceram uma visão importante sobre o ambiente interno da empresa.

Um aspecto que chamou atenção dos pesquisadores é que a empresa não utiliza estratégia de produção em nenhum horizonte de tempo, à medida que as vendas são efetuadas o material é projetado e fabricado. Funcionários afirmaram que os prazos de entrega prometidos aos clientes muitas vezes não são cumpridos, sendo entregues com atraso. A justificativa da equipe para não trabalhar com capacidade/planejamento é que não consegue observar um padrão de comportamento da demanda.

O balanço da empresa é realizado por meio de uma planilha de dados financeiros que registra o faturamento mensal, porém esse instrumento não se relaciona com setores de planejamento para análise conjunta.

O MPS (Plano Mestre de Produção) trata-se de uma declaração da quantidade e momento em que os produtos finais devem ser produzidos (SLACK, 2002). Na empresa estudada existe uma planilha que registra os dados de previsão de data de conclusão dos produtos, porém ela é mantida com o setor financeiro e não compartilhada com o setor de produção. Isso gera uma defasagem na comunicação entre as áreas da empresa e acaba por sobrecarregar o dono nas questões de gestão.

A outra ferramenta amplamente utilizada em PCP é o MRP (Planejamento de Recursos de Produção), que indica quanto e quando as matérias primas precisam estar disponíveis. Esse tipo 
de instrumento não é utilizado pela empresa em questão, pois a cada venda efetuada os recursos de produção são requisitados individualmente. Essa situação acaba por aumentar os custos de pedido, uma vez que são realizadas diversas ligações de solicitação de materiais, onerando tempo dos funcionários, são pagos muitos fretes para entrega e assim por diante.

Em se tratando dos sistemas de controle de ordens, para Fernandes e Filho (2010), envolve a liberação de ordens de produção e compra e também sequenciar as tarefas nas máquinas. $\mathrm{Na}$ empresa do estudo de caso, as ordens de produção são geradas pelo setor administrativo/ financeiro e enviadas ao departamento de projeto, para que finalize o projeto. Esse projeto detalhado ainda é devolvido para o setor administrativo para a elaboração de um projeto executivo e repassado para a área de design, que é responsável por fazer a última validação com o cliente e fazer a programação/ sequenciamento das atividades no chão de fábrica.

Essa organização das atividades operacionais ocorre no sistema Wrike, que organiza o fluxo de trabalho com um gráfico gantt. Porém, esse sistema não é capaz de medir os tempos e informações detalhadas sobre cada processo de produção e gerar informações gerenciais comparativas e agregadas entre os fluxos de produção da empresa.

O controle das atividades a partir do momento que a ordem de produção chega no chão de fábrica é realizado por um funcionário designado que toma as decisões necessárias nesse nível. Foi relatado que um antigo funcionário conseguia realizar isso de forma a otimizar o trabalho, mas com a sua saída da empresa isso não acontece mais de forma eficaz.

Ao observarmos os estoques da empresa concluímos que não há uma organização e controle rigoroso. A responsável pela compra, por exemplo, não tem informações rápidas e precisas sobre os estoques de matéria prima, e, a forma de disposição dos produtos acabados já incorreu em acidentes com o produto que o danificou.

Dada a situação estudada, podemos desenvolver um diagnóstico da situação da empresa que demonstram possibilidades de melhorias de automação por meio de um software:

- Não é realizada previsão de demanda;

- O MPS é realizado pelo setor financeiro (médio prazo);

- O planejamento da capacidade para viabilizar a produção estimada não é realizado;

- Não é realizado planejamento de compra de matéria-prima;

- A programação da produção é realizada em um sistema (curto prazo);

- O controle da produção é realizado uma pessoa, sem documentação;

- Não se conhece a capacidade produtiva ao certo; 
- A emissão de ordens é realizada pelo setor financeiro;

- O controle de estoques é incipiente;

- Utiliza sistema isolados, que não geram informações gerenciais;

- As decisões são centralizadas no dono da empresa;

\section{CONCLUSÃO}

O objetivo geral deste trabalho era analisar o processo de levantamento de requisitos necessários para um produto de software e estudar o contexto do Planejamento e Controle da Produção de uma pequena empresa do DF e, de acordo com o desenvolvimento do artigo, consideramos que os objetivos foram atingidos.

De acordo com a literatura analisada podemos compreender a correlação do PDP com o processo de desenvolvimento de softwares especialmente no que diz respeito à identificação de necessidades dos clientes e tradução dessas informações em requisitos do cliente e do produto. A partir dos dados levantados no estudo de caso realizado na empresa de metal design, indicam que essa instituição possui um processo de PCP incipiente, sem padronização e eficiência. Os sistemas de informações utilizados são desconectados e servem apenas para organização de informações de clientes em negociação de proposta e de atividades a serem feitas na produção, porém não reúnem as informações sobre as principais atividades de PCP: carregamento, sequenciamento e programação, tampouco apoiam as decisões de planejamento.

Um aspecto relevante observado é o comportamento do sócio fundador que, fascinado pelo seu negócio, realiza atividades sensíveis do nível operacional, que não confia em nenhuma outra pessoa para fazê-la. Entendemos que essa atitude compromete as decisões pertinentes ao nível estratégico, que não são bem definidas na empresa.

Os pesquisadores pretendem, em estudos futuros, observar se o padrão identificado neste estudo de caso se repete em outras micro e pequenas empresas de produção de bens, com o intuito de levantar necessidades comuns a organizações deste segmento para ter informações suficientes para transformá-las em requisitos de cliente e de produto.

\section{REFERÊNCIAS}

CORRÊA, H. L.; GIANES, G. N. I.; CAON, M. Planejamento, programação e controle da produção. São Paulo: Atlas, 2006. 
FERNANDES, F. C. F.; FILHO, M. G. Planejamento e Controle da Produção: Dos Fundamentos ao Essencial. São Paulo: Atlas, 2010.

FONSECA, A. J. H. Sistematização do processo de obtenção das especificações de projeto de produtos industriais e sua implementação computacional, 2000, 198 f. Tese (Doutorado em Engenharia Mecânica) - Centro Tecnológico, Universidade Federal de Santa Catarina, Florianópolis, 2000.

GIL, A. C. Como Elaborar Projetos de Pesquisa. 4 Ed. São Paulo: Atlas, 2002.

HERZWURM, G.; SCHOCKERT, S. The leading edge in QFD for software and eletronic business. International Journal of Quality \& Reliability Management, v. 20, n. 1, p. 36-55, 2003.

LAURENCE, P. F.; PAGE, A. L. Principles vc. Practice in New Product Planning. Journal of Product Innovation Management. Nova Iorque, p. 43-55, 1984.

LUSTOSA, L. J.; DE MESQUITA, M. A.; OLIVEIRA, R. J. Planejamento e Controle da Produção. São Paulo: Elsevier, 2008.

MAÇANEIRO, M. B. CUNHA, J. C. Os Modelos Technology-Push e Demand-Pull e as Estratégias de Organizações Ambidestras: a Adoção de Inovações Tecnológicas por Empresas Brasileiras. Revista Capital Científico. Guarapuava, v. 9, n. 1, 2011.

MACHADO, F. N. R. Análise e Gestão de Requisitos de Software: ondem nascem os sistemas. 3 ed. São Paulo: Erica, 2016.

MARTINS, P. G. Administração da Produção. 2 Ed. São Paulo: Saraiva, 2006.

NICKEL, E. M.; FERREIRA, M. G. G.; FORCELlini, F. A.; SANTOS, C. T.; SILVA, R. A. A. Modelo multicritério para referência na fase de Projeto Informacional do Processo de Desenvolvimento de Produtos. Gestão e Produção, São Carlos, v. 17, n. 4, p. 707-720, 2010.

PRESSMAN, R.; BRUCE, M. Engenharia de Software, 3 Ed. São Paulo: Makron Books do Brasil, 1995.

PRODANOV, C. C., \& de FREITAS, E. C. Metodologia do trabalho científico: métodos e técnicas da pesquisa e do trabalho acadêmico. 2 ed. Novo Hamburgo: Editora Feevale, 2013.

ROZENFELD, H. ; FORCELLINI, F. A. ;AMARAL, D. C. ; TOLEDO, J. C. ; SILVA, S. L. ; ALLIPRANDINI, D. H. ; SCALICE, R. K. Gestão de Desenvolvimento de Produtos : Uma referência para a melhoria do processo. São Paulo : Saraiva, 2006.

SCHRAMM, W. Notes on case studies of instructional media projects. The Academy for Educational Development: Washington, DC, 1971.

SEBRAE. Confira as diferenças entre micro empresa, pequena empresa e MEI. 2019. Acesso em: 6/6/10. Disponível em: <http://www.sebrae.com.br/sites/PortalSebrae/artigos/entenda-as-diferencas-entre-microempresapequena-empresa-e-mei,03f5438af1c92410VgnVCM100000b272010aRCRD>

SLACK, N. Administração da Produção. 2 Ed. São Paulo: Atlas, 2002.

ULIANA, R.; PLÍNIO, S. S.; BARBALHO, S. C. M.; ROZENFELD, H. Análise do processo de definição de requisitos em uma empresa de base tecnológica. In: Congresso Brasileiro de Gestão de Desenvolvimento de Produtos, 9, Natal (RN), 2013.

YIN, R. K. Estudo de Caso: Planejamento e métodos. Porto Alegre: Bookman, 2015. 